\title{
Federal Aviation Administration
}

DOT/FAA/AM-10/3

Office of Aerospace Medicine

Washington, DC 20591

\section{The Effects of Testing Circumstance and Education Level on MMPI-2 Correction Scale Scores}

Clara A. Williams

Raymond E. King

Civil Aerospace Medical Institute Federal Aviation Administration Oklahoma City, OK 73125

February 2010

Final Report 


\section{NOTICE}

This document is disseminated under the sponsorship of the U.S. Department of Transportation in the interest of information exchange. The United States Government assumes no liability for the contents thereof.

This publication and all Office of Aerospace Medicine technical reports are available in full-text from the Civil Aerospace Medical Institute's publications Web site: www.faa.gov/library/reports/medical/oamtechreports 



\section{Contents}

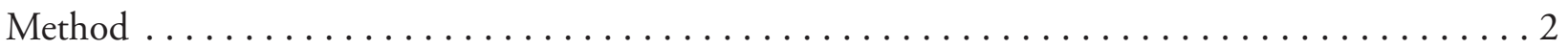

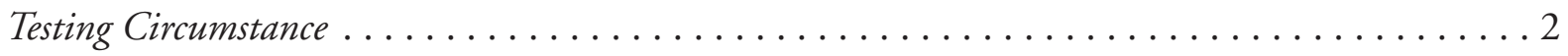

Education Level ...................................... 2

Results ..................................... 4

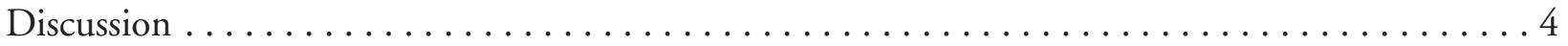

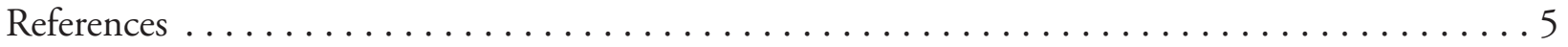

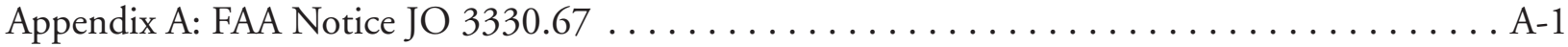





\section{The Effects of Testing Circumstance and Education Level on MMPI-2 Correction SCALE SCORES}

The Minnesota Multiphasic Personality Inventory-2 (MMPI-2) is used by the Federal Aviation Administration (FAA) as a screening method to detect psychopathology in air traffic control specialist (ATCS) applicants (FAA Notice JO 3330.67, see Appendix A). The MMPI-2 is administered after a conditional offer of employment is extended, in accordance with the Americans with Disabilities Act of 1990 (1991). Such a method is termed "select out" and is part of the entry medical examination, as described by King, Schroeder, Manning, Retzlaff, and Williams (2008). Applicants are disqualified on the basis of the presence of a personality disorder or other psychiatric conditions, including substance abuse, which poses a "potential hazard to safety in the Air Traffic Control System" (page 4, Appendix 1, FAA Order 3930.3A). The MMPI-2 is only used as a screening tool. Identified applicants are then assessed by a more comprehensive battery of psychological tests, as well as a diagnostic interview conducted by an independent-practice, licensed clinical psychologist, paid by the FAA.

MMPI-2 profiles are interpreted by examining the various clinical scales after a consideration of the validity indicators. One such validity indicator, the $K$ scale, is a measure of "faking good." The $K$ scale was originally developed by Meehl and Hathaway (1946). Through a series of analyses, Meehl and Hathaway determined optimal " $K$ corrections" to be made to selected clinical scales in order to make the final scores more accurately reflect the known psychopathology of the criterion group. In other words, $K$ was developed as a way to ensure that those individuals with psychopathology would have appropriately elevated clinical scales. Greene summarizes Meehl and Hathaway's work as a way to accurately "differentiate persons known to have psychopathology who were hospitalized and yet obtained normal profiles from normal individuals who for some reason obtained elevated profiles" (Greene, 2000, p. 11).

Consideration of the $K$ scale score can help to determine the extent to which an individual's responses to items are attempting to mask problems and difficulties. Certain clinical scales of the MMPI- 2 can be adjusted or corrected by adding the predetermined fractions (Butcher, Graham, Ben-Porath, Dahlstrom, \& Kaemmer, 2001) of an individual's $K$ scale. The clinical scales and the fractional raw-score additive values of $K$ are shown in Table 1.

Table 1. Descriptions of the five clinical scales that are $K$ corrected and fractional values of $K$.

\begin{tabular}{|l|c|}
\hline Clinical Scales $^{\mathrm{a}}$ & $K$ values $^{\mathrm{b}}$ \\
\hline $\begin{array}{l}\text { Scale } 1-\text { Hypochondriasis. High scores reflect individuals who have an excessive } \\
\text { number of vague nonspecific complaints and body concerns (G/I, fatigue, pain, and } \\
\text { general weakness). }\end{array}$ & .5 \\
\hline $\begin{array}{l}\text { Scale 4- Psychopathic Deviate. High scores reflect difficulty in incorporating the values } \\
\text { and standards of society, may exhibit asocial or antisocial behaviors, impulsiveness, and } \\
\text { need for immediate gratification. May be a bit elevated in younger test takers as a normal } \\
\text { function of late adolescence. }\end{array}$ & .4 \\
\hline $\begin{array}{l}\text { Scale } 7-\text { Psychasthenia. High scores reflect individuals experiencing a great deal of } \\
\text { psychological turmoil and discomfort. They tend to be anxious, tense, and agitated. They } \\
\text { are worrisome individuals with difficulty concentrating. }\end{array}$ & 1.0 \\
\hline $\begin{array}{l}\text { Scale } 8-\text { Schizophrenia. High scores are reflective of bizarre mentation, delusions, and } \\
\text { possibly hallucinations. Confused thinking, poor judgment, and alienation are common. }\end{array}$ & 1.0 \\
\hline $\begin{array}{l}\text { Scale } 9-\text { Hypomania. High scores are suggestive of over-activity, poor impulse control, } \\
\text { irritability, and possible aggressive outbursts. }\end{array}$ & .2 \\
\hline \\
a Graham, 1990 \\
${ }^{\mathrm{a}}$ Butcher, Graham, Ben-Porath, Dahlstrom, and Kaemmer, 2001
\end{tabular}


To gain an understanding of how a test-taker's true psychological functioning is estimated by correcting the clinical scales, refer to Figure 1. As described above, a fraction of the $K$ score (see left margin for "Fractions of $K^{\prime \prime}$ ) is added to the clinical scales (see bottom of page for procedure to add fractions of $K$ to the clinical scales) to arrive at the $K$-corrected raw score, which is then plotted to obtain the $\mathrm{T}$ score (normed to have a mean of 50 and standard deviation of 10).

For example, someone with a raw $K$ score of 25 would have $13(.5 K)$ points added to Scale $1,10(.4 K)$ points added to Scale 4, 25 (1K) points added to scales 7 and 8 , and $5(.2 K)$ points added to Scale 9. The "Raw Score with $K^{\prime \prime}$ (bottom line) is then plotted to arrive at the $K$ corrected T score for the clinical scale. The $K$ scale is so routinely used that it is included in the first 370 items known as the "abbreviated version" of the MMPI-2. Administration of this shorter version permits scoring of all clinical scales and allows $K$ correction of scales 1 , $4,7,8$, and 9 .

Graham (2006) reports that some practitioners caution that one must be especially careful in using $K$ corrections in circumstances where defensiveness is common (e.g., employment screening), claiming that artificially inflated profiles can result. Practitioners may, therefore, need to avoid using $K$ corrections in non-clinical evaluations. Butcher (1990) reports that other practitioners argue that correcting MMPI-2 profiles gives a more accurate measure of an individual's defensiveness. While assessors are interested in the level of an applicant's defensiveness to gain a truer functional estimate, it is important to not unnecessarily inflate clinical scales in non-clinical settings. It is, therefore, important to understand the source of the $K$. If applicants are rendering profiles that are unduly defensive, then it would be prudent to use modified instructions to explain the role of the validity scales to help the applicants answer in a more straight-forward fashion (Butcher, Morfitt, Rouse, \& Holden, 1997).

According to Graham (1990), it is not unusual for college-educated individuals who are not being defensive (masking problems) to obtain $K$-scale $\mathrm{T}$ scores in a range of 55 to 60 . Individuals with even more formal education may obtain $T$ scores in the range of 60 to 70 (Graham, 1990). According to Graham, the level of $K$ can be influenced by factors such as socioeconomic status, as well as education, and is not strictly a measure of defensiveness.

The present study will gauge the influence of testing circumstance (i.e., research participation vs. employment screening) on $K$ scores. Our hypothesis is that those who are being screened for employment will be more defensive and, thus, earn higher $K$ scores than those who are only participating in a research study with no job jeopardy.
The influence of education on the value of $K$ will also be examined. We predict that the value of $K$ will increase in this sample as years of education increase, as predicted by Graham (1990).

\section{Method}

\section{Testing Circumstance}

Group 1 consisted of 1,014 FAA ATCS students in training at the FAA Academy in Oklahoma City, OK, who voluntarily completed the MMPI-2 as part of a research project. There were $794(78.3 \%)$ males and 220 $(21.7 \%)$ females in Group 1. They were administered the standard 567-item paper-and-pencil test. This group had not previously been administered the MMPI-2; they were medically screened using the FAA-modified 16PF with nonstandard scoring method, which eliminated virtually no candidates (King, Retzlaff, Detwiler, Schroeder, \& Broach, 2003; King, Schroeder, Manning, Retzlaff, \& Williams, 2008).

Group 2 consisted of 2,374 tentatively hired ATCS candidates who completed the MMPI-2 as part of their medical screening process. This group of 1,914 (80.6\%) males and 460 (19.4\%) females received the abbreviated computerized administration of the MMPI-2 via the FAA Intranet. All the $K$-scale items were present in the abbreviated test administration. All clinical and $K$-scale items were presented in the same order for each version of the test.

\section{Education Level}

Having a high school diploma is a pre-requisite to be hired as an ATCS. Many applicants attended College Training Initiative (CTI) programs, which are hosted by two-year (community) and four-year colleges. For Group 1, years of education were not reported consistently due to a misunderstanding of the demographics portion of the MMPI-2 by the participants. Therefore, the analysis on level of education was not conducted on Group 1. Most members of Group 2 more accurately reported their level of education due to an explicit chart the authors developed. This chart demonstrated how to convert education attainment into a number (high school diploma equals 12 years of education, one year of college equals 13 years of education, etc.) and was included in the instructions introducing the MMPI-2.

Sixteen of 2,374 total cases were excluded from Group 2 because they had failed to identify their level of education. Non-gender norms were used because the purpose of this research is to support personnel selection. The Civil Rights Act of 1991 states that it is an unlawful employment practice to use gender-specific norms in personnel selection. 


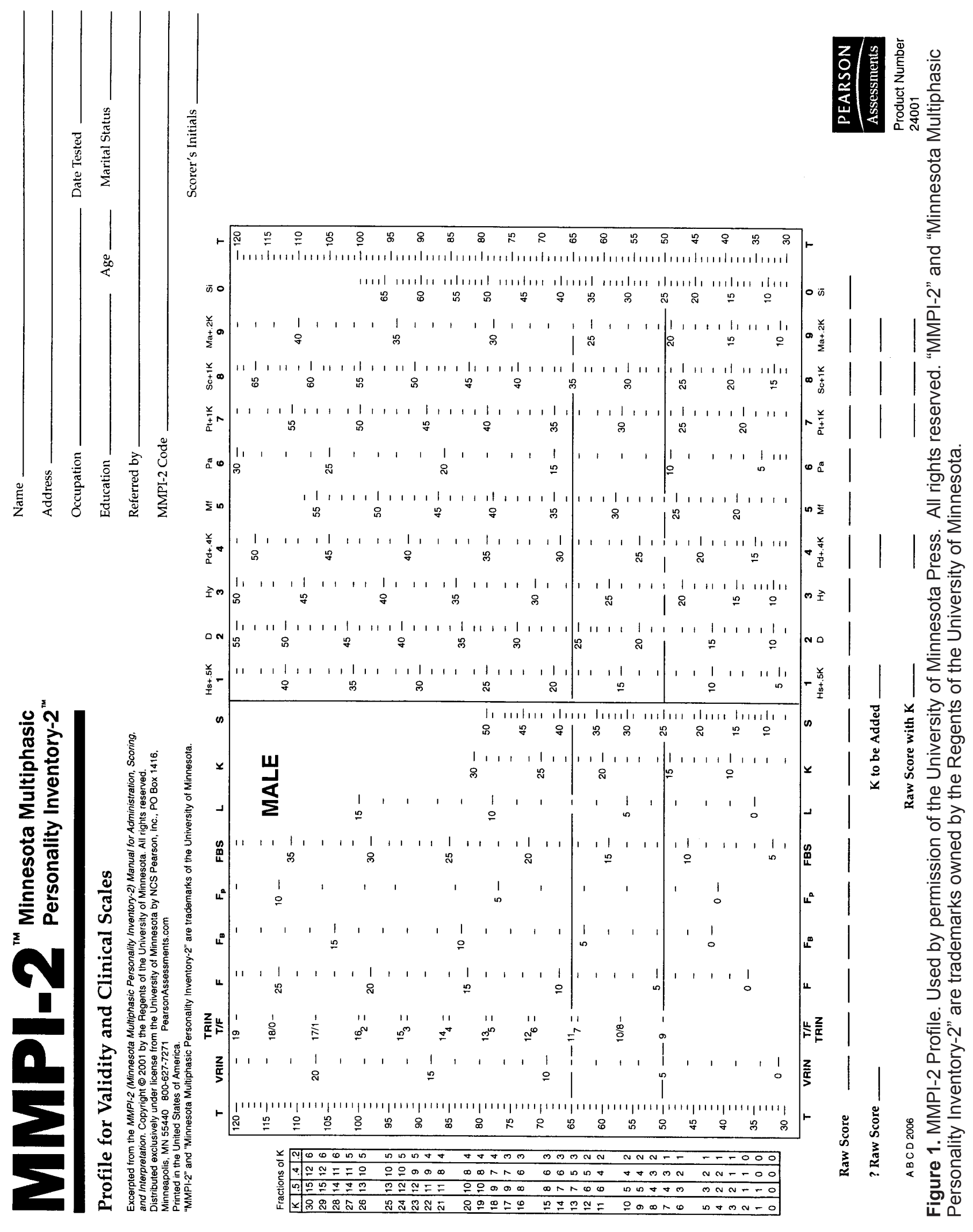


Table 2. Descriptive statistics for $K$ by Years of Education for Group 2.

\begin{tabular}{|cccc|}
\hline Years of Education & Number & $K$ - Mean & $K$ - Std. Deviation \\
\hline 12 & 333 & 61.5 & 7.5 \\
\hline 13 & 279 & 61.5 & 7.4 \\
\hline 14 & 453 & 62.6 & 7.4 \\
\hline 15 & 251 & 61.9 & 7.8 \\
\hline 16 & 894 & 62.2 & 7.5 \\
\hline 17 & 80 & 62.8 & 8.5 \\
\hline 18 & 68 & 63.3 & 7.3 \\
\hline
\end{tabular}

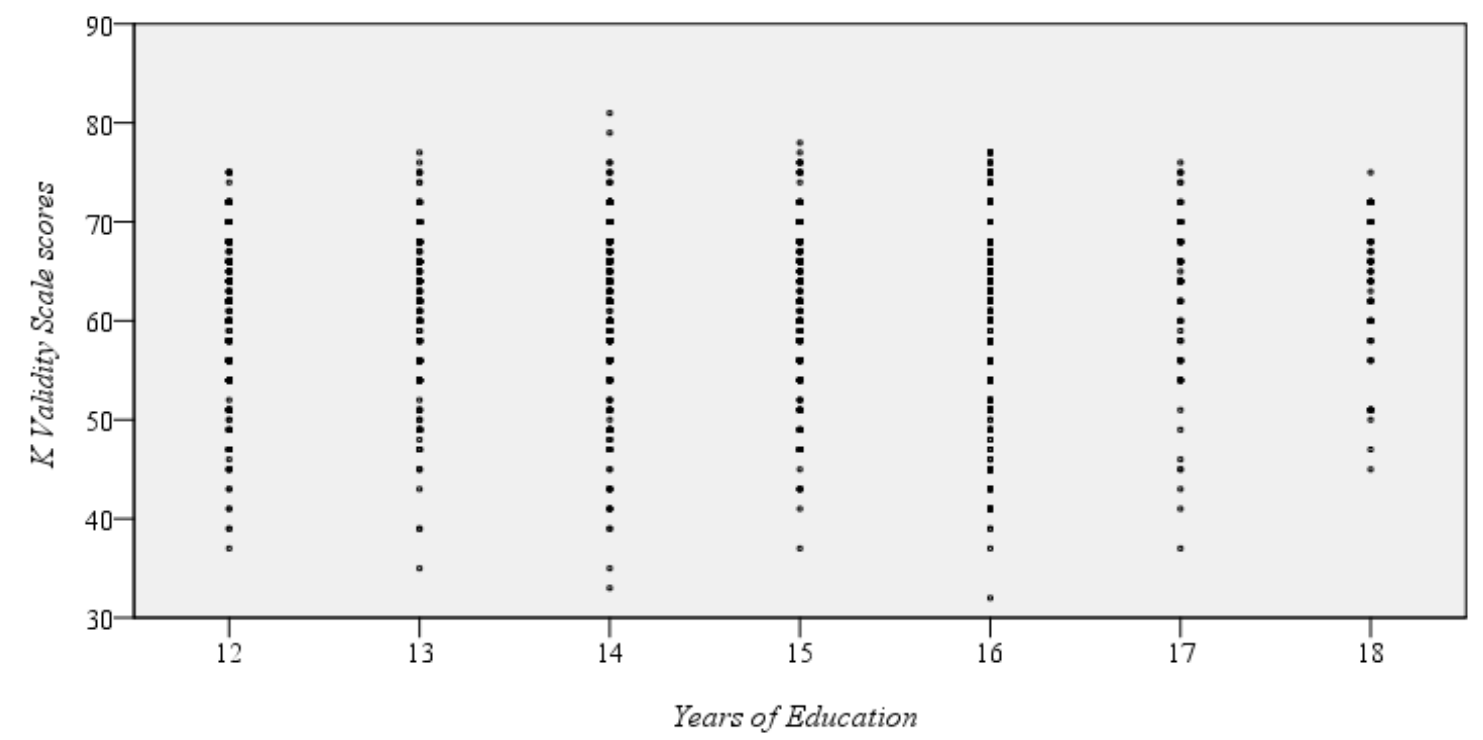

Figure 2. Relationship between $K$ scale scores and years of education for Group 2.

\section{Results}

The overall mean (with standard deviations in parentheses) of the $K$ scale for Group 1 was 57.15 (9.295); for Group 2 it was 62.10 (7.526). This difference was significant, $t(1,609.77)=-14.97, p=.0001$. There was approximately half of a standard deviation $(-4.95)$ difference between the groups. According to Cohen (1988), this is a small-to-medium effect size.

Table 2 shows that 2,358 candidates in Group 2 indicated their level of education. There were 1,904 males and 454 females. Two thousand forty-one candidates indicated that they had more than 12 years of education (indicating some college). The remaining 333 candidates indicated 12 years of education.

The group's $K$ scale T-scores ranged from 32 to 81 . An analysis using Pearson's correlation coefficient (2-tailed) indicated no significant linear relationship between the $K$ scale scores and years of education $(r=.04, p=.06)$. Figure 2 shows a plot of the relationship between $K$ scale scores and years of education for the group.

\section{Discussion}

This research suggests that $K$ did not increase as level of education increased, at least when measured for ATCS job applicants. The level of education in this group, however, was relatively range-restricted, as every participant had at least 12 years of education, and most had either 14 or 16 years of education as a function of their hiring source (the College Training Initiative). While it is unfortunate that this research effort could not gauge the effect of education in the voluntary research participants due to their misunderstanding of how to convert grade level to number of years of education, in all likelihood, the level of education was roughly equivalent between Groups 1 and 2 , as they were recruited from similar sources.

This research was also not able to measure the participants' socioeconomic status. In one sense, they were more alike than different as they were young job applicants who presumably were not particularly financially secure. Nevertheless, the applicants likely came from a variety of backgrounds, from relatively financially insecure to quite well-off. Perhaps these unmeasured differences exerted 
an influence on Scale $K$. Future research should measure socioeconomic status (SES) as directly as possible (considering background SES, as well as current SES) and compare it to level of $K$.

The hypothesis that there is a significant difference between the two groups in terms of their scale $K$ scores was supported. Job applicants were likely much more motivated to present themselves favorably, due to the effects of the score on their chance of being hired. "Passing" the MMPI-2 meant that there would be one fewer obstacle to secure employment in a lucrative profession. Under these conditions, it is understandable that a scale that measures "faking good" would be elevated. Thus, Group 2 likely had elevated levels of $K$ due to defensiveness. Modifying the instructions that introduce the MMPI-2 might help reduce the level of $K$ by reducing defensiveness (Butcher, Morfitt, Rouse, \& Holden, 1997), either on initial presentation or on re-tests during second-tier assessment.

This research suggests that elevations of $K$ in ATCS applicants are more likely due to defensiveness, rather than years of education. The implications of this research include some support for using the $K$ scale to correct the clinical scales with ATCS applicants. Continuing to use $K$ to correct the clinical scales would be in keeping with the intent to correct for defensiveness when a test taker is asked to report his or her psychiatric symptoms and other potentially embarrassing information. Defensiveness results in under-reporting of symptoms; therefore, $K$ correction serves a useful function by bringing the clinical scales to the level that they would be at if the test taker were not being defensive. Future research should investigate if the $K$ fractional values that have been traditionally used (and reported in Table 1 and Figure 1 here) are optimal when the MMPI-2 is being used as part of a selection procedure, rather than in a clinical setting.

It is true that a job applicant's defensiveness may result in profiles that suggest more psychopathology, where less actually exists due to the $K$ correction. That is why no applicant is ever eliminated on the basis of the results of the MMPI-2 alone. All applicants identified with the MMPI-2 are afforded, at the FAA's expense, a more extensive assessment that may include a re-administration of the MMPI-2 (with explicit instructions on how to respond in a less defensive fashion), as well as other testing and a clinical interview. It is important to keep in mind that $K$ correcting has long been an accepted practice; the point of this study was for practitioners to better understand the sources and utility of $K$ when dealing with an employment applicant population.

\section{References}

Americans with Disabilities Act of 1990, Pubic Law No.101-336, \$2, 104 Stat. 328 (1991). (www. ada.gov)

Butcher, J.N. (1990). The MMPI-2 in psychological treatment. NY: Oxford.

Butcher, J.N., Graham, J.R., Ben-Porath, Y.S., Dahlstrom, W.G., \& Kaemmer, B. (2001). MMPI-2 (Minnesota Multiphasic Personality Inventory-2) manual for administration, scoring, and interpretation, revised edition. Minneapolis, MN: NCS Pearson.

Butcher, J.N., Morfitt, R.C., Rouse, S.V., \& Holden, R.R. (1997). Reducing MMPI-2 Defensiveness: The effect of specialized instructions on retest validity in a job applicant sample. Journal of Personality Assessment, 68, 385-401.

Civil Rights Act of 1991, Public Law No 102-166 (1991). (www.eeoc.gov/policy/cra91.html)

Cohen, J. (1988). Statistical power analysis for the behavioral sciences (2nd Ed.). Hillsdale, NJ: Erlbaum.

Federal Aviation Administration (1980, May 9). FAA Order 3930.3A - Air traffic control specialist health program. Washington, DC: U.S. Government Printing Office.

Federal Aviation Administration (2008, February 28). FAA Notice JO3330.67-Guidance for administering psychological screening evaluations of tentatively selected air traffic controlspecialist candidates. (https:// employees.faa.gov/tools_resources/orders_notices/ index.cfm?fuseaction+c.dspDocumentInformation \&documentID=73513)

Graham, J.R. (1990). MMPI-2: Assessing personality and psychopathology, $2^{\text {nd }}$ edition. New Haven, NY: Oxford.

Graham, J.R. (2006). MMPI-2: Assessing personality and psychopathology, 4th edition. New Haven, NY: Oxford.

Greene, R.L. (2000). The MMPI-2: An interpretive manual, $2^{\text {nd }}$ Edition. Needham Heights, MA: Allyn \& Bacon.

King, R.E., Retzlaff, P.D., Detwiler, C.A., Schroeder, D.J., $\&$ Broach, D. (2003). Use of personality assessment measures in the selection of air traffic control specialists. (DOT/FAA/AAM-03/20). Washington, DC: FAA Office of Aerospace Medicine. 
King, R.E., Schroeder, D.J., Manning, C.A., Retzlaff, P.D., \& Williams, C.A. (2008). Screening air traffic control specialists for psychopathology using the Minnesota Multiphasic Personality Inventory-2. (DOT/ FAA/AM-08/13). Washington, DC: FAA Office of Aerospace Medicine.

Meehl, P.E., \& Hathaway, S.R. (1946). The K factor as a suppressor variable in the MMPI. Journal of Applied Psychology, 30, 525-564. 


\section{APPENDIX A}

FAA Notice JO 3330.67 - Guidance for Administering Psychological Screening Evaluations of Tentatively Selected Air Traffic Control Specialist Candidates 



\section{NOTICE}

\section{U.S. DEPARTMENT OF TRANSPORTATION FEDERAL AVIATION ADMINISTRATION}

Air Traffic Organization Policy
N JO 3330.67

Effective Date: $02 / 28 / 08$

Cancellation Date:

02/28/09

SUBJ: Guidance for Administering Psychological Screening Evaluations of Tentatively Selected Air Traffic Control Specialist Candidates

1. Purpose of This Notice. This notice provides procedures and direction for administering the computerized Minnesota Multiphasic Personality Inventory-2 (MMPI-2) psychological screening evaluation as part of the overall medical evaluation of all tentatively selected air traffic control specialist (ATCS) candidates.

2. Distribution. All Air Traffic Managers

3. Where Can I Find a Copy of this Notice? You can find a copy of this notice on MYFAA employee website: http://employees.faa.gov/tools_resources/orders_notices/.

\section{Background.}

a. The FAA has administered a paper and pencil psychological test, the $16 \mathrm{PF}$, to identify candidates who may be unfit for safety positions in the National Airspace System (NAS). The Air Traffic Organization (ATO) wants to enhance its ability to identify candidates who have a disqualifying psychiatric condition that could compromise aviation safety. Therefore, the FAA has selected the MMPI-2 as the new psychological screening test.

b. The Vice Presidents for Terminal Services and En Route and Oceanic Services allocate staffing for new hires in accordance with the Controller Workforce Plan (CWP).

c. Selection and placement of tentatively selected candidates has been centralized for ATCSs. The Aviation Careers Division, as the servicing Human Resources organization, collects all coordinated pre-employment clearances in accordance with agency policies and procedures for medical and security approvals for ATCS hires.

d. Centralized Selection Panels (CSPs) comprised of Air Traffic selecting officials convene to make tentative selections for positions as ATCSs. Once the tentatively selected ATCSs have been interviewed and their selection confirmed by receipt of the interview template, Terminal 
Services and En Route and Oceanic Services will identify the appropriate test proctors as indicated in paragraph 4 of this notice.

e. Once the ATCS new hires have received their formal tentative offer letter from the Aviation Careers Division, they will proceed with completing documentation for both their security and medical clearances. The MMPI-2 psychological screening evaluation is part of the medical examination.

\section{Proctoring MMPI-2 Psychological Evaluations.}

a. MMPI-2 test proctor responsibilities are described in the attachment of this notice. Terminal Services and En Route and Oceanic Services will identify the appropriate test proctors for the MMPI-2 who will be physically located in the ATO Service Center offices, the Mike Monroney Aeronautical Center, the William J. Hughes Technical Center, Air Route Traffic Control Centers, District Offices, FAA Regional Office locations, Headquarters, and some Terminal Services facilities. Test proctors will be trained by CAMI personnel (Dr. Raymond King and Clara Williams) to administer the MMPI-2 using the extensive, step-by-step instructions that have been developed and field tested. Test proctors will be able to administer the MMPI-2 via a CITRIX server, as well as using locally installed software in the event that the CITRIX server is inoperative. Proctors will also be trained to administer the MMPI-2 in its booklet and paper answer sheet form.

b. Test proctor responsibilities include identifying appropriate testing space, validating the identity of the candidate by checking a government issued photo identification card, accessing the MMPI- 2 software on-line for the candidate, monitoring the candidate during the testing, and providing technical assistance if needed. Proctors will be instructed on the proper and secure method for capturing responses in the

MMPI-2 database for scoring by the Civil Aerospace Medical Institute (CAMI). Test proctors will not have the capacity to score the MMPI-2 under any method of administration, as that ability will always rest with the licensed psychologist who is supervising the psychological assessment portion of the medical exam and who is in a contractual agreement with the MMPI-2 publisher to supervise scoring.

c. The ATO Acquisition and Business Services Technical Training and Development (AJA) staff will contact candidates to schedule the MMPI-2 tests and will notify the designated facility representative. Each test proctor will access the MMPI- 2 test through the www.faa.gov website (see attachment). Only ATCS candidates who have received a tentative offer letter from the Aviations Careers Division will be given the MMPI- 2 test. Candidates typically take 45 minutes to complete the 370 test questions and submit their responses. The test responses are captured in the MMPI-2 database for scoring and the results are incorporated into the Regional Flight Surgeons' medical examination decisions.

d. A candidate who does not clear the MMPI-2 screen will be informed by the Regional Flight Surgeon and referred to a conveniently located, independent-practice psychologist who has been identified by the FAA through his or her inclusion in the National Register of Health Service Providers in psychology (www.findapsychologist.org) or through a state or local 
psychological association or state licensure board for additional assessment if the candidate desires further hiring consideration. The results of this second level psychological screening will be sent to the FAA licensed clinical psychologist in the Office of Aerospace Medicine Medical Specialties Division (AAM-200) for review.

e. Upon successful completion of all medical evaluations, the regional medical division will notify the Aviation Careers Division of the medical clearance status of each candidate and will send the medical file to the gaining region's medical division.

6. Disposition. Questions concerning this notice should be directed to the ATO Acquisition and Business Services AJA staff at (202) 267-7133. Questions concerning the MMPI-2 examination should be referred to CAMI at (405) 954-4846. Questions about proctor passwords or problems accessing the MMPI-2 should be referred to the ATO Acquisition and Business Services Data Services helpdesk at (405) 954-4002.

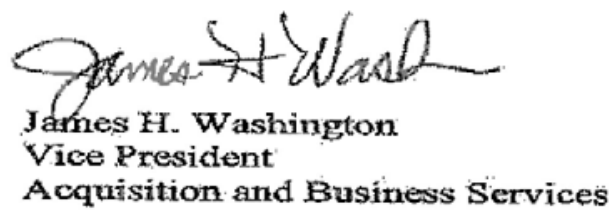

Attachment 
